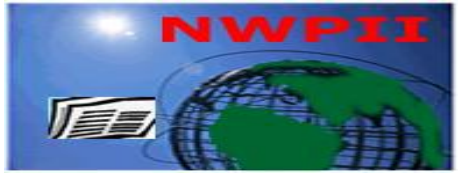

\title{
Glyceamic and Oxidative Stress Markers in Different Haptoglobin Phenotypes of A Type-2 Diabetics' Population in Nigeria
}

\author{
Olayinka O. Olaniyan ${ }^{1 *}$, Odeyinka O. Odewusi², Humphrey B. Osasdolor ${ }^{3}$ \\ ${ }^{1}$ Department of Chemical Pathology, Osun State University, Osogbo, Osun State \\ ${ }^{2}$ Department of Medical Laboratory Science, Afe-Bablola University, Ado-Ekiti, Ekiti State \\ ${ }^{3}$ Department of Medical Laboratory Science, University of Benin, Benin City, Edo State \\ *Corresponding Author \\ O.O. Olaniyan \\ Department of Chemical Pathology, \\ Osun State University, \\ Osogbo, Osun State \\ Nigeria \\ Cell Phone: +2348034766014 \\ Email:olacube2001@gmail.com
}

Received:01 May 2020; | Revised:10 May 2020; | Accepted:04 September 2020

\begin{abstract}
Diabetes has long been known to be synonymous with body oxidative stress and development of vascular complications. Different clinical functions including oxidative capabilities have been credited to the different haptoglobin polymorphism. This study is aimed at finding possible association between haptoglobin gene polymorphism, glyceamic control indices and antioxidants parameters in Nigerian type 2 diabetics. The study included 170 subjects divided into three groups of 60 type 2 diabetics without any vascular complications, 60 type 2 diabetics with various vascular complications, and 50 age and sex matched apparently healthy subjects. All participants were subjected to full history taking, complete clinical examination, and routine laboratory investigations. Haptoglobin phenotypes, glyceamic control index and antioxidant parameters were measured in all subjects. Hp1-1 polymorphic type 2 diabetics show good glyceamic control indices than Hp2-1 and Hp 2-2 individuals. Likewise, Hp2-2 polymorphic type 2 diabetics show significantly reduced antioxidant potentials than Hp2-1 and Hp1-1 polymorphic individuals. Hp 2-2 polymorphism is a likely genetic predisposing factor contributing to development of diabetes vascular complications via low antioxidant level. Awareness of this gene susceptibility should raise future research for proper treatment and prevention of vascular complications in diabetics.
\end{abstract}

Keywords: Haptoglobin polymorphism, Antioxidant, type 2 diabetes, Vascular complications, Glyceamic control 


\section{Introduction}

Diabetes mellitus (DM) is a major health challenge worldwide and a rising epidemics in Nigeria, with long-term diabetes vascular complications as the leading cause of morbidity and mortality in these individuals ${ }^{[1]}$. Type 2 diabetes, the commonest form of diabetes disease in Nigeria ${ }^{[2]}$, resulted from continuous or gradual development of insulin resistance accompanied with or without a relative deficiency in insulin secretion resulting from $\beta$-cell dysfunction, to cause hyperglycaemia [3]. Chronic hyperglycaemia, a primary feature of diabetes mellitus leads to the overproduction of mitochondrial reactive oxygen species (ROS) and subsequent formation of sustained cellular oxidative stress, due to increased oxidant production (accumulation of free electrons) and/or decreased antioxidant activity (such as glutathione and superoxide dismutase) ${ }^{[4,5]}$. Hyperglycaemia also increases the lipid peroxidation and non enzymatic protein glycosylation $[6,7]$, causing changes that stimulate the production of inflammatory cytokines which has been implicated in morphological and pathological changes found in macro and micro vascular diabetes complications ${ }^{[8]}$.

Haptoglobin (Hp), a major positive acute phase glycoprotein [9], that binds free oxygenated haemoglobin released from erythrocytes in response to inflammation or infection. It also undergoes glycation and it is expressed as a genetic polymorphism comprising of two alleles denoted as 1 and 2 to give rise to three major polymorphism / phenotypes commonly referred to as Hp1-1, Hp2-1, and Hp2-2 in humans ${ }^{[10-12]}$. Circulating $\mathrm{Hp}$ complexes is an aggregate (polymer) of stoichiometrically dependent Hp monomers. The protein products of homozygote $\mathrm{Hp} 1$ allele crosslink only with one other Hp1 monomer to form a dimeric protein product whereas, the $\mathrm{Hp} 2$ allele protein can cross link with two distinct $\mathrm{Hp}$ monomers to form either a homozygous protein product which can be cyclic trimers, quatermers and pentamers or heterozygote (2 haptoglobin and 1 monomers) protein product of liner trmers, quatermers and pentamers of mixtures of $\mathrm{Hp} 1$ and Hp2 products ${ }^{[13]}$. Hp is involved in preventing the generation of hemoglobin-driven hydroxyl and lipid peroxides radicals ${ }^{[14]}$, the protective ability of haptoglobin against haemoglobin driven oxidative injury is evident when haemoglobin becomes glycated, (a process that is markedly accelerated in the diabetics state) forming glycohemoglobinhaptoglobin complexes which are catalytically redox active ${ }^{[15]}$, and therefore the rate at which haptoglobin-haemoglobin complexes are cleared from the serum and extra-vascular space is of believed to be haptoglobin dependent and of heightened importance in the diabetic state.

Several prospective and cross-sectional population studies have demonstrated that haemoglobin scavenger receptor, CD163 (monocyte-macrophage scavenger receptor) provides a mechanism by which $\mathrm{Hp}-\mathrm{Hb}$ complexes are being cleared in the body system ${ }^{[16]}$. This clearance however, has been attributed to affect oxidative capacity among different Hp polymorphic individuals with an observation that $\mathrm{Hp} 1-1-\mathrm{Hb}$ complexes are being cleared more rapidly than $\mathrm{Hp} 2-1 \mathrm{Hb}$ and $\mathrm{Hp} 2-2 \mathrm{Hb}$ complexes and subsequently reduces the burden of oxidative vascular damage among Hp1-1individuals than Hp2-1 and Hp2-2 individuals [13,17-19]. Despite an extensive research in the field of diabetes, a limited number of these researches have linked Hp genetic polymorphism to development of diabetes and its vascular complications. Also to our knowledge, the Hp gene polymorphism has not been linked to glyceamic and oxidative parameters. The aim of this study was to find an association between Hp gene polymorphism, glyceamic control indices and antioxidants parameters among Nigerian type 2 diabetics.

\section{Materials and Methods}

\subsection{Research design and subjects}

The study protocol was approved by the Osun State University Health Research Ethics Committee. Consents were sought and obtained from all participants and all procedures were in accordance to Helenski declaration and guidelines. 120 confirmed and known type 2 diabetes mellitus patients attending Diabetes clinic at a tertiary health institution in Osogbo, Nigeria were studied and divided into 2 groups of 60 diabetics without vascular complications (DM-VC, 25males and 35 females) and another 60 diabetics with vascular 
complications (DM+VC, 20 males and 40 females). Apparently healthy 50 volunteers were recruited among the staff of Osun State University to serves as normal controls (NC, 20 males and 30 females). Exclusion criteria included subjects who had a diagnosis of type 1 diabetes, or any other disease other than type 2 diabetes, abnormal liver functions, chronic inflammatory diseases, acute infections, hematologic disorders, acutely ill patients, malignancy, and pregnant women.

Each patient was subjected to full physical examination aside their clinical history including their demographic data and major traditional diabetes factors tracing (age, sex, hypertension, dyslipidemia, family history of diabetes), educational and treatment history were recorded using a structured questionnaire. Participants were also weighed with a weighing scale to the nearest $0.5 \mathrm{~kg}$ in light clothing without shoes and their heights measured using a stadiometer to the nearest $0.5 \mathrm{~cm}$. Body mass index (BMI) was calculated by the Quetelet' $s$ index, as weight $(\mathrm{kg}) /$ height2 (m2). The mean of two blood pressure (BP) readings, measured on the left arm after participants had rested for 5 min on a sitting position was recorded using mercury sphygmomanometers (Accoson). Hypertension was defined as systolic blood pressure $\geqslant 140 \mathrm{mmHg}$ or diastolic blood pressure $\geqslant 90$ $\mathrm{mmHg}$ or self reported use of antihypertensive medication [20]. Dyslipidemia, was defined according to NCEP expert panel report ${ }^{[21]}$, type 2 diabetes diagnosis was based on the World Health Organization criteria ${ }^{[22]}$, and vascular disease was defined using standard clinical protocol as complications (retinopathy, diabetic foot, neuropathy, nephropathy or cardiovascular disease) which resulted after development of type 2 diabetes in an individual.

\subsection{Blood Sampling and biochemical analysis}

After overnight fasting of 10 hours blood samples were collected from patients and control subjects into both heparinized vacutainer and a fluoride oxalate bottle for biochemical analysis and centrifuged at $3000 \mathrm{rpm}$ for $15 \mathrm{~min}$, aliquots of the plasma were stored at $-80^{\circ} \mathrm{C}$ until analysis though, glycated haemoglobin (HbAlc) and haptoglobin (Hp) gene polymorphism was done sane day. All spectrophotometric assays were done on JenwayR.
UV- 6302 spectrophotometer, while chemicals for the analysis were sourced from Sigma-Aldrich, UK.

Haptoglobin polymorphism: Haptoglobin gene polymorphism was demonstrated using polyacrylamide gel electrophoresis-PAGE as previously described ${ }^{[23]}$. Briefly, $6 \mu \mathrm{L}$ of plasma sample was incubated with $1 \mu \mathrm{L}$ of standard erythrocyte haemolysate of washed human red blood cells. $6 \mu 1$ of loading buffer was then added to the mixture and $8 \mu \mathrm{L}$ from the resultant mixture were loaded onto the gel for electrophoresis, after migration, proteins were fixed using $10 \%$ trichloroacetic acid solution and stained with benzidine solution. The bands were then observed for Hp phenotype fractions.

Glyceamic controls: Glycated haemoglobin (HbAlc) in whole blood and plasma glucose (FPG) were estimated using ion exchange resin [Spectrum Diagnostics, Egypt, (Ref: 254 003)] and enzymatic glucose oxidase hydrolysis [Randox, UK, (Cat No: GL364)] kits respectively.

Oxidative stress parameters: Plasma total antioxidant concentration (pTAC) was measured using the modified method of Benzie and Strain ${ }^{[24]}$, as reported by Kaushik et al ${ }^{[25]}$, the method is based on the ability of plasma antioxidants to reduces $\mathrm{Fe} 3+-\mathrm{TPTZ}$ to Fe2+-TPTZ.

Erythrocyte Glucose-6-Phosphate dehydrogenase (eG6PD) activity was determined using a commercially available kit [Randox, UK, (Cat No: PD 410)], where eG6PD reduces NADP to $\mathrm{NADPH}$ and the rate of reduction of NADP+ was measured at $340 \mathrm{~nm}$.

Erythrocyte glutathione (eGSH) level was determined using modified method of Chakrabarty et al ${ }^{[26]}$, where glutathione in the protein-free red cell lysates react with DTNB solution to form a colour complex measured at $412 \mathrm{~nm}$.

Plasma malondialdehyde (MDA) level was measured spectrophotometrically at $523 \mathrm{~nm}$ using the method of Song et al ${ }^{[27]}$, where MDA in protein free plasma precipitate form a pink colour chromogen with thiobarbituric acid (TBA).

Erythrocyte superoxide dismutase (eSOD) activity was however determined using the protocols of Engwa et al ${ }^{[28]}$, based on the ability of SOD to inhibit pyrogallol autoxidation. 


\subsection{Statistical analysis}

Qualitative and quantitative data collected from diabetics with or without complications, and control subjects were presented as frequencies/percentages and the mean \pm SD (standard deviation) respectively. The distributions of $\mathrm{Hp}$ phenotypes among the groups were represented using bar graphs. Comparison of quantitative normally distributed data between the polymorphism groups were analyzed using student ' $t$ ' and one way analysis of Variance (ANOVA) tests, $p$-value was considered statistically significant when it is less than 0.05. GraphPad 8.0 statistical software was used for the analysis.

\section{Results}

\subsection{Population Characteristics}

This study comprised 120 type 2 diabetes mellitus patients and 50 apparently healthy individuals. 60 of the diabetics had various documented vascular complications [Diabetes eye complications of retinopathy and cataract in 31 $(25.83 \%)$ and $8(6.67 \%)$ patients respectively, 14
$(11.67 \%)$ had diabetes neuropathy, nephropathy was present in $2(1.67 \%)$ individuals while, diabetes coronary heart disease and diabetic foot were indicated in $3(2.50 \%)$ and $2(1.67 \%)$ patients respectively] while the remaining 60 diabetics have no vascular complication (Figure 1).

Table 1, shows a not significantly $(p>0.05)$ reduced number of diabetics with vascular complications having less number of subjects with family history of diabetes and also a not significantly $(\mathrm{p}>0.05)$ higher number of individuals suffering from hypertension, and dyslipidaemia than diabetics without vascular complications. BMI data and duration of diabetes among type 2 diabetics with vascular complications were significantly higher $(p<0.05)$ than those without vascular complications. There was no significant difference in terms of mean age of the study groups. Diabetes groups showed significantly higher systolic and diastolic blood pressures of both SBP and DBP $(\mathrm{p}<0.001)$ compared to controls. Diabetics with vascular complications have significantly $(p<0.05)$ and not significantly $(\mathrm{p}>0.05)$ higher DBP and SBP values respectively when compared to those without vascular complications.

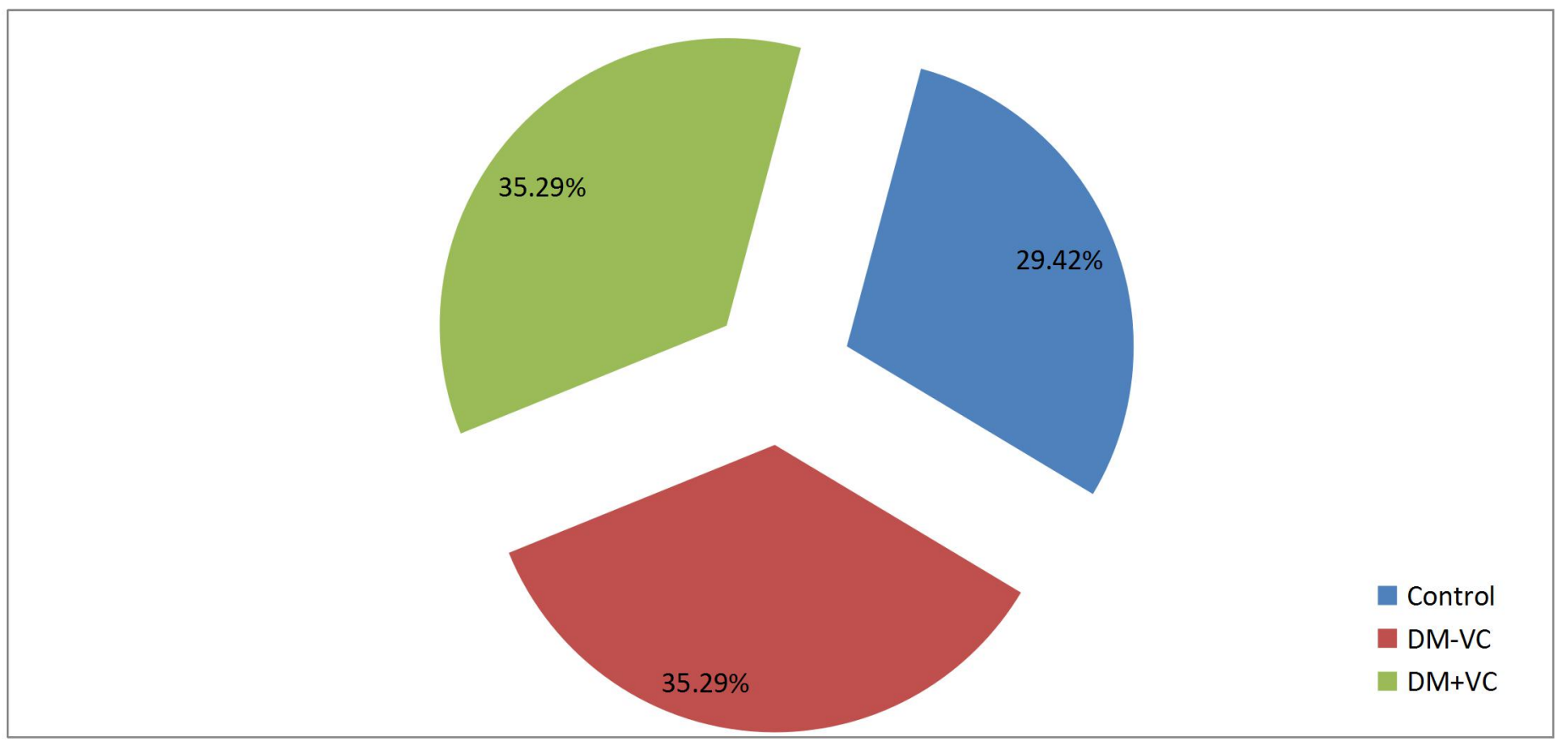

Figure 1: Distribution of subjects in the study population 
Table 1: Risk factors, demographic and laboratory data of the study population

\begin{tabular}{llll}
\hline Parameters & $\begin{array}{c}\text { Control } \\
\mathrm{n}=50\end{array}$ & $\begin{array}{c}\text { DM-VC } \\
\mathrm{n}=60\end{array}$ & $\begin{array}{c}\mathrm{DM}+\mathrm{VC} \\
\mathrm{n}=60\end{array}$ \\
\hline Sex (male/female) & $20 / 30_{\mathrm{a}}$ & $25 / 35_{\mathrm{a}}$ & $20 / 40_{\mathrm{a}}$ \\
Diabetes duration (yrs) & NA & $4.43 \pm 2.55_{\mathrm{a}}$ & $6.67 \pm 2.84_{\mathrm{b}}$ \\
BMI $\left(\mathrm{kg} / \mathrm{m}^{2}\right)$ & $20.91 \pm 0.85_{\mathrm{a}}$ & $24.86 \pm 3.43_{\mathrm{b}}$ & $26.56 \pm 4.61_{\mathrm{c}}$ \\
Family history of DM & NA & $35(58.33)_{\mathrm{a}}$ & $32(53.33)_{\mathrm{a}}$ \\
Hypertension [n (\%)] & NA & $4(6.67)_{\mathrm{a}}$ & $9(15)_{\mathrm{a}}$ \\
Dyslipidemia [n (\%)] & NA & $8(13.3)_{\mathrm{a}}$ & $12(20)_{\mathrm{a}}$ \\
Age (years) & $54.16 \pm 9.61_{\mathrm{a}}$ & $53.97 \pm 9.71_{\mathrm{a}}$ & $53.35 \pm 8.41_{\mathrm{a}}$ \\
SBP (mm/Hg) & $117.00 \pm 13.48_{\mathrm{a}}$ & $130.65 \pm 8.71_{\mathrm{b}}$ & $130.58 \pm 8.38_{\mathrm{b}}$ \\
DBP $(\mathrm{mm} / \mathrm{Hg})$ & $83.70 \pm 4.77_{\mathrm{a}}$ & $87.73 \pm 5.16_{\mathrm{b}}$ & $90.13 \pm 5.05_{\mathrm{c}}$ \\
Haptoglobin Polymorphism & & & \\
\multicolumn{1}{c}{$1-1[\mathrm{n}(\%)]$} & $23(46)_{\mathrm{a}}$ & $8(13.33)_{\mathrm{b}}$ & $3(5)_{\mathrm{b}}$ \\
\multicolumn{1}{c}{$2-1[\mathrm{n}(\%)]$} & $21(42)_{\mathrm{a}}$ & $33(55)_{\mathrm{a}}$ & $24(40)_{\mathrm{a}}$ \\
$2-2[\mathrm{n}(\%)]$ & $6(12)_{\mathrm{a}}$ & $19(31.76)_{\mathrm{b}}$ & $33(55)_{\mathrm{c}}$
\end{tabular}

Result expressed as mean $\pm \mathrm{SD}, \mathrm{n}=$ number of subjects per group, $(\%)=$ percentage of subjects per group

$\mathrm{BMI}=$ body mass index, $\mathrm{SBP}=$ Systolic blood pressure, $\mathrm{DBP}=$ Diastolic blood pressure

$\mathrm{NA}=$ Not applicable

$\mathrm{p}<0.05$ is statistically significant (values with different subscripts a, b, c along a row are significantly different from each other)

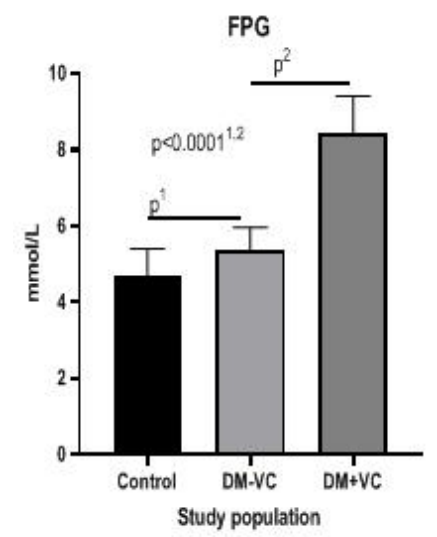

eSOD

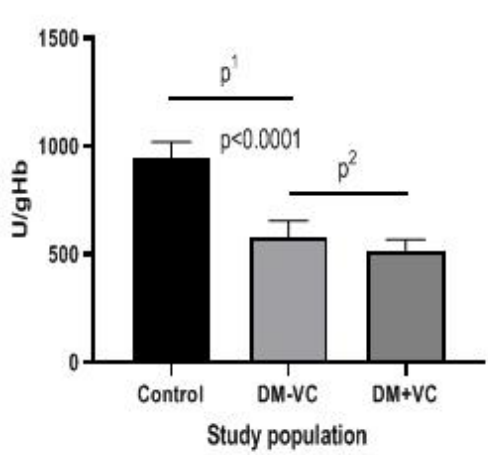

HbA1c

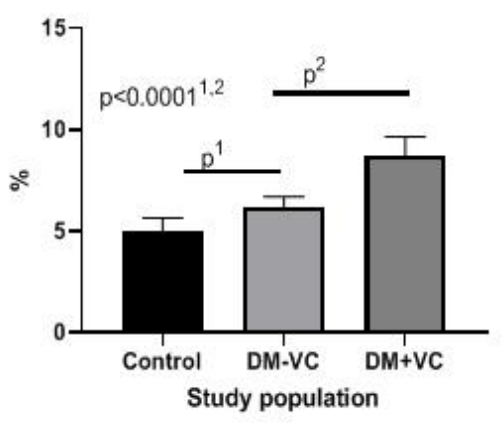

eG6PD

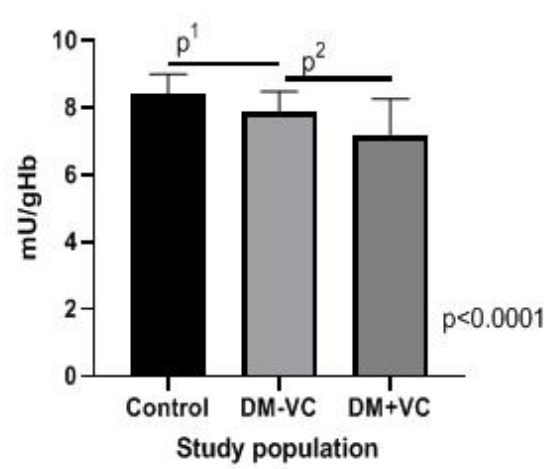

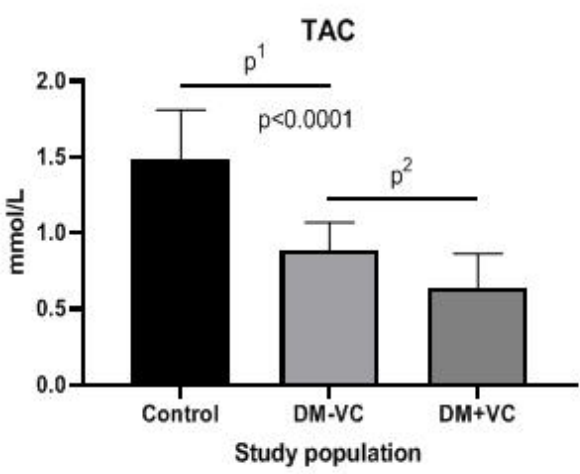

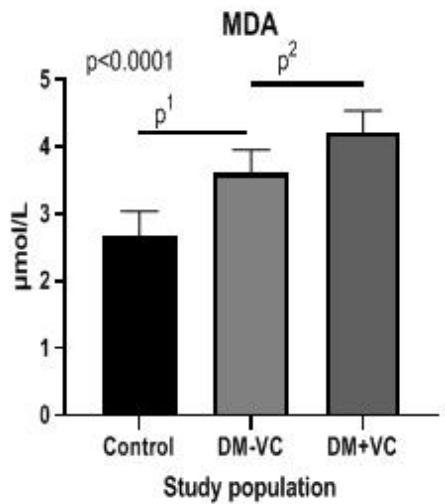

Figure 2: Glyceamic and antioxidants parameters in different study population 
Table 2: Measured parameters in different haptoglobin phenotypes of type 2 diabetics

\begin{tabular}{lllll}
\hline Parameters & & \multicolumn{3}{c}{ Haptoglobin phenotypes } \\
\cline { 2 - 5 } & $\begin{array}{c}\text { Total patients } \\
(\mathrm{n}=120)\end{array}$ & $\begin{array}{l}\text { Hp 1-1 } \\
(\mathrm{n}=11)\end{array}$ & $\begin{array}{l}\text { Hp 2-1 } \\
(\mathrm{n}=57)\end{array}$ & $\begin{array}{l}\text { Hp 2-2 } \\
(\mathrm{n}=52)\end{array}$ \\
\hline Age $($ years $)$ & $53.38 \pm 9.38$ & $52.36 \pm 10.16_{\mathrm{a}}$ & $53.40 \pm 9.66_{\mathrm{a}}$ & $54.39 \pm 8.20_{\mathrm{a}}$ \\
BMI $\left(\mathrm{kg} / \mathrm{m}^{2}\right)$ & $25.71 \pm 4.13$ & $23.56 \pm 3.82_{\mathrm{a}}$ & $24.91 \pm 3.16_{\mathrm{a}}$ & $27.11 \pm 4.76_{\mathrm{b}}$ \\
Diabetes duration (yrs) & $4.55 \pm 2.91$ & $3.59 \pm 1.66_{\mathrm{a}}$ & $4.93 \pm 2.70_{\mathrm{b}}$ & $6.67 \pm 2.98_{\mathrm{c}}$ \\
Hypertension n $(\%)$ & $13(10.83)$ & $2(18.18)_{\mathrm{a}}$ & $3(5.27)_{\mathrm{a}}$ & $8(15.38)_{\mathrm{b}}$ \\
Dyslipidaemia $\mathrm{n}(\%)$ & $20(33.33)$ & $3(15)_{\mathrm{a}}$ & $4(20)_{\mathrm{a}}$ & $13(65)_{\mathrm{b}}$ \\
FPG $(\mathrm{mmol} / \mathrm{L})$ & $6.92 \pm 1.74$ & $5.90 \pm 1.21_{\mathrm{a}}$ & $6.63 \pm 1.71_{\mathrm{a}}$ & $7.45 \pm 1.72_{\mathrm{b}}$ \\
HbA1c $(\%)$ & $7.43 \pm 1.49$ & $6.26 \pm 1.08_{\mathrm{a}}$ & $7.14 \pm 1.44_{\mathrm{b}}$ & $7.92 \pm 1.48_{\mathrm{c}}$ \\
pTAC $(\mathrm{mmol} / \mathrm{L})$ & $0.76 \pm 0.24$ & $1.03 \pm 0.13_{\mathrm{a}}$ & $0.78 \pm 0.24_{\mathrm{b}}$ & $0.68 \pm 0.21_{\mathrm{c}}$ \\
eSOD $(\mathrm{u} / \mathrm{gHb})$ & $551.09 \pm 69.33$ & $614.27 \pm 70.64 \mathrm{a}$ & $562.12 \pm 68.70_{\mathrm{b}}$ & $525.63 \pm 59.35_{\mathrm{c}}$ \\
eGSH $(\mathrm{mg} / \mathrm{gHb})$ & $64.67 \pm 3.54$ & $68.20 \pm 2.86_{\mathrm{a}}$ & $66.43 \pm 3.40_{\mathrm{a}}$ & $64.76 \pm 3.50_{\mathrm{b}}$ \\
MDA $(\mu \mathrm{mol} / \mathrm{L})$ & $3.92 \pm 0.44$ & $3.63 \pm 0.35_{\mathrm{a}}$ & $3.81 \pm 0.47_{\mathrm{a}}$ & $4.09 \pm 0.36_{\mathrm{b}}$ \\
eG-6-PD $(\mathrm{mU} / \mathrm{gHb})$ & $6.18 \pm 1.85$ & $7.91 \pm 0.32_{\mathrm{a}}$ & $7.96 \pm 0.54_{\mathrm{a}}$ & $8.08 \pm 0.73_{\mathrm{a}}$ \\
\hline ReSul exprssed
\end{tabular}

Result expressed as mean $\pm \mathrm{SD}, \mathrm{n}=$ number of subjects per group and $(\%)=$ percentage of subjects per group $\mathrm{BMI}=$ body mass index $\quad \mathrm{eSOD}=$ erythrocyte superoxide dismutase

$\mathrm{FPG}=$ Fasting plasma glucose $\mathrm{HbA} 1 \mathrm{c}=$ Glycated haemoglobin

$\mathrm{SBP}=$ Systolic blood pressure $\quad \mathrm{TAC}=$ Total antioxidant concentration

$\mathrm{DBP}=$ Diastolic blood pressure $\quad$ eGSH $=$ erythrocyte glutathione

eG-6-PDH: erythrocyte Glucose-6-phosphate dehydrogenase

$\mathrm{p}<0.05$ is statistically significant (values with different subscripts $\mathrm{a}, \mathrm{b}, \mathrm{c}$ along a row are significantly different from each other)

\subsection{Relationship between haptoglobin phenotypes, risk factors and measured parameters in type 2 diabetics}

From figure 2 FPG, HbA1c and eG-6-PD were significantly higher in diabetics with vascular complications compared to diabetics without vascular complications $(\mathrm{p}<0.001)$ and control subjects $(p<0.001)$. On the other hand, TAC, eSOD and eGSH levels were significantly decreased in diabetics with vascular complications compared to controls $(<0.001)$ and diabetics without vascular complications $(p<0.001)$. However, the number of subjects with $\mathrm{Hp}$ 1-1 polymorphism was significantly higher in control subjects as compared to diabetics with $(\mathrm{p}<0.001)$ and without vascular complications $(p<0.001)$. Likewise, Hp 2-2 polymorph was significantly higher among type 2 diabetics with vascular complications than those without vascular complications $(p<0.001)$ and control subjects $(\mathrm{p}<0.05)$ (Table 2$)$.

\section{Discussion}

Despite significant advances in preventive efforts and medical care geared towards diabetes mellitus treatment / management, vascular disease (either micro or macro) continues to disproportionately affect individuals living with this disease thus, signalling genetic predisposition as a key factor in the development of vascular complications ${ }^{[29]}$. This study was an extension of our previous study ${ }^{[23]}$ which provides data on Hp phenotypes and type 2 diabetes mellitus in Nigerians with a view of determining if the glyceamic control indices and oxidative stress parameters in type 2 diabetics were $\mathrm{Hp}$ polymorphism/phenotype driven.

The glyceamic control (FPG and $\mathrm{HbAlc}$ ) parameters measured in this study were significantly high in Hp2-2 diabetics than Hp1-1 individuals. Another finding from this study was that Hp1-1 has good antioxidant properties than Hp2-1 and Hp2-2 in decreasing order. Haptoglobin is likely to be exerting its oxidative protective role via the differences in the phenotypic molecular size and shape of the protein products encoded by the two different Hp alleles. Smaller Hp complexes are believed to quickly mobilise into the extracellular space and undergo glomerular sieving better than the larger $\mathrm{Hp}^{[13]}$. 
The mechanism of Hp1-1 exhibiting better good glyceamic and oxidative properties than other Hp polymorphs is not fully known but can be partially explained on the basis that hyperglycaemia (which is more pronounced in Hp2-2) caused increased body oxidation leading to generation of more reactive oxygen species (ROS) thereby causing depletion of total body antioxidant system. The generated ROS however, initiate the steps involved in pro-inflamatory vascular damage and consequential increase in tissue/vascular damage within the body system among diabetics.

In order words, Hp 2-2 polymorphism role in development of vascular complications in diabetes can be attributed to inefficient scavenging mechanism exhibited by the $\mathrm{Hp} 2-2 \mathrm{Hb}$ complex which binds the free haemoglobin through Fenton reaction at a lesser extent (to $\mathrm{Hp} \mathrm{1-1} \mathrm{Hb}$ complex through CD163) with less clearance by the haemoglobin scavenger receptor $[15,16]$ thereby promoting LDL damage within the blood vessels (a characteristics of early stage endothelia dysfunction in type 2 diabetes) ${ }^{[30]}$.

\section{Conclusion}

This study, to our knowledge, was among the first to attempt the association between haptoglobin phenotypes and antioxidant parameters among diabetics in Nigeria population thereby advocating Hp phenotyping among diabetics. Thus, we suggest further study with large data base as to further elucidate our findings. Summarily, screening of type 2 diabetes for $\mathrm{Hp}$ phenotypes would be an essential therapeutic monitoring tool in patient focus treatment as $\mathrm{Hp} 2$ allele and $\mathrm{Hp} \quad 2-2$ polymorphism is a marker to development of type 2 diabetes and vascular complications.

\section{Conflicts of Interest}

This research did not receive any grant from funding agencies in the public, commercial, or notfor-profit sectors. The authors report no conflict of interest. The data from this research is available to be shared upon request.

\section{Authors Contributions}

Conception or design: Olaniyan OO

Acquisition, analysis, or interpretation of data: Olaniyan OO, Odewusi OO, Osadolor HB

Drafting the work or revising: Olaniyan OO, Odewusi OO

Critical revision of the manuscript for important intellectual content: Olaniyan OO, Osadolor, HB

Final approval of the manuscript: Olaniyan OO, Odewusi OO, Osadolor HB

\section{ORCID}

$\begin{array}{lll}\begin{array}{c}\text { Olaniyan } \\ \text { 1576-3222 }\end{array} & \text { OO } & \underline{\text { https://orcid.org/0000-0003- }} \\ \begin{array}{c}\text { Odewusi } \\ \frac{9346-810}{\text { Osadolor }}\end{array} & \text { OO } & \underline{\text { https://orcid.org/0000-0001- }} \\ \underline{4079-5218} & & \underline{\text { https://orcid.org/0000-0003- }}\end{array}$

\section{Acknowledgments}

We thank all the patients that participated in this study. We also thank colleagues at the Laboratory Complex of the College of Health Sciences, Osun State University for dedicated measurements of biochemical parameters.

\section{References}

1 Ogbera AO, Ekpebegh C. Diabetes mellitus in Nigeria: The past, present and future. World $\boldsymbol{J}$ Diabetes 2014; 5(6): 905-911 DOI: 10.4239/wjd.v5.i6.905

2 Olamoyegun M, Ibraheem W, Iwuala S, Audu M, Kolawole B. Burden and pattern of micro vascular complications in type 2 diabetes in a tertiary health institution in Nigeria. $\boldsymbol{A} \boldsymbol{f r}$ Health Sci. 2015;15(4):1136-1141

3 Kumari MK,Devi MU. Evaluation of Oxidative Stress in Type 2 Diabetics with Vascular Complications. IOSR J Dent Med Sci. 2016;15(2):28-32. doi:10.9790/0853-15292832

4 Olaniyan OO, Osadolor HB. Erythrocyte G6PD activity and GSH level as risk factors for vascular complications among type 2 diabetics in Osogbo, Nigeria. Alexandria $\boldsymbol{J}$ Med. 
2019;55(1):95-99.

doi: $10.1080 / 20905068.2019 .1688986$

$5 \mathrm{Xu}$ Y, Osborne BW, Stanton RC. Diabetes causes inhibition of glucose-6-phosphate dehydrogenase via activation of PKA, which contributes to oxidative stress in rat kidney cortex. Am J Physiol Renal Physiol 2005; 289(5): F1040-1047 [PMID: 15956780 DOI: 10.1152/ajprenal.00076.2005]

6 Olaniyan OO, Osadolor HB. Blood lipid peroxidation and DNA damage in a Nigerian population of type 2 diabetics. Sokoto J Med Lab Sci. 2019;4(3):29-36.

7 Nawale RB, Mourya VK, Bhise SB. Nonenzymatic glycation of proteins: A cause for complications in diabetes. Indian J Biochem Biophys. 2006;43(6):337-344

8 Giugliano D, Ceriello A, Paolisso G. Oxidative stress and diabetic vascular complications. Diabetes Care 1996; 19(3): 257-267 [PMID: 8742574 DOI: 10.2337/diacare.19.3.257]

9 Hamdy G, Hendy OM, Mahmoud H, El-sebaey A, Ali SR, Khalaf FA. Haptoglobin phenotypes as a risk factor for coronary artery disease in type 2 diabetes mellitus: An Egyptian study. Egypt J Med Hum Genet. 2014. doi:10.1016/j.ejmhg.2014.03.003

10 Lee SH, Jeong S, Lee J, Yeo IS, Oh MJ, Kim U, Kim S, Kim SH, Park SY, Kim JH, Park SH, Kim JH, An HJ. Glycomic profiling of targeted serum haptoglobin for gastric cancer using nano LC/MS and LC/MS/MS. Mol Biosyst 2016; 12(12): 3611-3621 [PMID: 27722599 DOI: $10.1039 / \mathrm{c} 6 \mathrm{mb} 00559 \mathrm{~d}]$

11 Amiri AA, Hashemi-Soteh MB, Haghshenas MR, Daneshvar F, Rastegar A, Farazmand T. Haptoglobin polymorphism in individuals with type 2 diabetic microangiopathy. $\mathbf{N} \mathbf{A m ~} \mathbf{J} \mathbf{M e d}$ Sci 2013; 5(9): 529-535 DOI: 10.4103/1947$\underline{2714.118929}$

12 Olaniyan OO, Osadolor HB. Haptoglobin Phenotypes and Association with Vascular Complications in Nigerian Type 2 Diabetes Patients. Am J Biomed Sci. 2018;10(3):184188. doi:10.5099/aj180300184

13 Nakhoul FM, Zoabi R, Kanter Y, Zoabi M, Skorecki K, Hochberg I, Leibu R, Miller B, LevyAP. Haptoglobin phenotype and diabetic nephropathy. Diabetologia. 2001;44:602-604
14 Sauerwein H, Schmitz S, Hiss S. The acute phase protein haptoglobin and its relation to oxidative status in piglets undergoing weaninginduced stress. Redox Rep 2005; 10(6): 295 302 DOI: $\underline{10.1179 / 135100005 X 83725}$

15 Asleh R, Marsh S, Shilkrut M, Binah O, Guetta J, Lejbkowicz F, Enav B, Shehadeh N, Kanter Y, Lache O, Cohen O, Levy NS, Levy AP. Genetically determined heterogeneity in hemoglobin scavenging and susceptibility to diabetic cardiovascular disease. Circ Res 2003; 92(11): 1193-1200 [PMID: 12750308 DOI: 10.1161/01.RES.0000076889.23082.F1]

16 Etzerodt A, Moestrup SK. CD163 and inflammation: biological, diagnostic, and therapeutic aspects. Antioxid Redox Signal 2013; 18(17): 2352-2363 DOI: 10.1089/ars.2012.4834

17 Levy AP, Hochberg I, Jablonski K, Resnick HE, Lee ET, Best L, Howard BV.Haptoglobin phenotype is an independent risk factor for cardiovascular disease in individuals with diabetes: The Strong Heart Study. J Am Coll Cardiol. 2002.

18 Suleiman M, Aronson D, Asleh R, Kapeliovich MR, Roguin A, Meisel SR, Shochat M, Sulieman A, Reisner SA, Markiewicz W, Hammerman H, Lotan R, Levy NS, Levy AP. Haptoglobin polymorphism predicts 30-day mortality and heart failure in patients with diabetes and acute myocardial infarction. Diabetes 2005; 54(9): 2802-2806 [PMID: 16123372 DOI: 10.2337/diabetes.54.9.2802]

19 Nakhoul FM, Miller-Lotan R, Awaad H, Asleh R, Levy AP. Hypothesis--haptoglobin genotype and diabetic nephropathy. Nat Clin Pract Nephrol 2007; 3(6): 339-344 [PMID: 17525716 DOI: 10.1038/ncpneph0467]

20 Amiri AA, Hashemi-Soteh MB, Haghshenas MR, Daneshvar F, Rastegar A, Farazmand T. Haptoglobin polymorphism in individuals with type 2 diabetic microangiopathy. $\mathbf{N}$ Am $\mathbf{J}$ Med Sci 2013; 5(9): 529-535 DOI: 10.4103/19472714.118929

21 Grundy SM, Stone NJ, Bailey AL, Beam C, Birtcher KK, Blumenthal RS, Braun LT, de Ferranti S, Faiella-Tommasino J, Forman DE, Goldberg R, Heidenreich PA, Hlatky MA, Jones DW, Lloyd-Jones D, Lopez-Pajares N, 
Ndumele CE, Orringer CE, Peralta CA, Saseen JJ, Smith SC, Jr., Sperling L, Virani SS, Yeboah J. 2018 AHA/ACC/AACVPR/AAPA/ABC/ACPM/AD A/AGS/APhA/ASPC/NLA/PCNA Guideline on the Management of Blood Cholesterol: Executive Summary: A Report of the American College of Cardiology/American Heart Association Task Force on Clinical Practice Guidelines. J Am Coll Cardiol 2019; 73(24): 3168-3209 DOI: 10.1016/j.jacc.2018.11.002

22 World Health organisation. Definition and Diagnosis of Diabetes Mellitus and Intermediate Hyperglycemia. Report of a WHO/IDF consultation. WHO Library Cataloguing-in- Publication Data. 2006; ISBN $\begin{array}{lllll}978 & 92 & 4 & 159493 & 6\end{array}$ https://www.who.int/diabetes/publications/Defi nition and diagnosis of diabetes new.pdf.

23 Olaniyan OO, Osadolor HB. Haptoglobin Phenotypes and Association with Vascular Complications in Nigerian Type 2 Diabetes Patients. Am J Biomed Sci. 2018;10(3):184188. doi:10.5099/aj180300184

24 Benzie IFF, Strain JJ. The Ferric Reducing Ability of Plasma (FRAP) as a Measure of "Antioxidant Power": Anal Biochem. 1996; 239(1):70-6.

25 Kaushik A,Jijta C,Kaushik JJ, Zeray R, Ambesajir A, Beyene L. FRAP (Ferric reducing ability of plasma) assay and effect of Diplazium esculentum (Retz) Sw. (a green vegetable of North India) on central nervous system. Indian J Nat Prod Resour. 2012;3(2):228-231.
26 Chakrabarty J, Vidyasagar M.S., Fernandes D, Bhat V, Nagalakshmi, Josia G SSM. Effectiveness of pranayama on the levels of serum protein thiols and glutathione in breast cancer patients undergoing radiation therapy: A randomized controlled trial. Indian $\boldsymbol{J}$ Physiol Pharmacol. 2013;57(3):225-232.

27 Song F, Jia W, Yao Y, Hu Y, Lei L, Lin J, Sun $\mathrm{X}$, Liu L. Oxidative stress, antioxidant status and DNA damage in patients with impaired glucose regulation and newly diagnosed Type 2 diabetes. Clin Sci (Lond) 2007; 112(12): 599-606 DOI: 10.1042/CS20060323

28 Engwa GA, Nwalo FN, Chibuzor GE, Ejiagha EC, Abonyi MC, Ugwu, TE, Obiudu KI, Agbafor KN, Ojo OO, Ubi BE. Relationship between Type 2 Diabetes and Glucose-6Phosphate Dehydrogenase (G6PD) Deficiency and Their Effect on Oxidative Stress. $\boldsymbol{J}$ Diabetes Metab. 2018;09(08):1-8. doi:10.4172/2155-6156.1000800

29 Costacou T, Levy AP. Haptoglobin genotype and its role in diabetic cardiovascular disease. J Cardiovasc Transl Res 2012; 5(4): 423-435 DOI: $10.1007 / \mathrm{s} 12265-012-9361-\mathrm{Z}$

30 Quaye IK, Ababio G, Amoah AG. Haptoglobin 2-2 Phenotype is a Risk Factor for Type 2 Diabetes in Ghana. J Atheroscler Thromb. 2006;13(2):90-94. 